Egyptian

Orthodontic Journal

\title{
THREE-DIMENSIONAL EVALUATION OF POSSIBLE MANDIBULAR FUNCTIONAL DISPLACEMENT IN CLASS II DIVISION 2 MALOCCLUSION SUBJECTS
}

\author{
Moataz A. Fathallah ${ }^{1}$, Walid A. El-Kenany ${ }^{2}$, \\ Hanan A. Ismail ${ }^{3}$, Mohammed I. Mowafy ${ }^{4}$
}

ABSTRACT:

Objective: The aim of this study is to evaluate the condyle-fossa relationship, using CBCT scanning before and after the correction of retroclined upper incisors in class II division 2 subjects, for the detection of possible mandibular functional displacement. Materials and Methods: The sample consisted of 11 Class II, division 2 subjects. Two CBCT scans were obtained for each subject; one before and one after leveling of the maxillary arch. Comparison of the joint space measurements was done for detection of condylar displacement. Results: Statistical Analysis of the sample showed statistically significant decrease in the anterior joint spaces, statistically significant increase in the superior joint space, the posterior joint spaces, and significant changes of the condylar position ratios and percentage. Conclusion: The correction of the maxillary Incisors retroclination of a Class II, Division 2 subjects lead to statistically significant change of the condylar position moving anteriorly and inferiorly. The clinical significance of these values is yet to be investigated.

1 - Post graduate student, Orthodontic department, Alexandria University.

2 - Professor of Orthodontics, Faculty of Dentistry, Alexandria University.

3 - Professor of Orthodontics, Faculty of Dentistry, Alexandria University.

4 - Assistant Professor of Orthodontics, Faculty of Dentistry, Alexandria University. 
Egyptian

Orthodontic Journal

Key Words: Class II Division 2, CBCT, Joint spaces, Condylar displacement.

\section{INTRODUCTION}

Owing to the little evidence, many authors disagreed with the idea that the correction of the incisor retroclination in Class II, Division 2 subjects will result in a forward mandibular movement. Several studies used the relationship between the retruded contact position, intercuspation, and rest position to study the effect of treatment of Class II, Division 2 malocclusion on the mandibular displacement. Ingervall, ${ }^{(1)}(1968)$ found no significant evidence to support that the mandible is locked in a distal position as a result of the maxillary central incisors angulations. Demisch, Ingervall and Thuer, ${ }^{(2)}$ (1992) found that the anteroposterior distance between the retruded and the intercuspal position did not change after proclination of the retroclined upper incisors and correction of the deep bite. Their results were considered as evidence that the mandible is not posteriorly displaced in these cases. Thüer et al, ${ }^{(3)}(1992)$ implicated electromyography and sirognathography to study the effect of treatment of Class II, Division 2 malocclusionon anterior mandibular positioning, their results did not reveal any sign to support this concept.

However, the literature reveals that it is a common belief that "unlocking" the mandible in Class II, Division 2 malocclusions allows correction of the distocclusion. ${ }^{(4,5)}$ Swann, ${ }^{(6)}$ (1954) estimated that one third of Class II, Division 2 cases had mandibular functional displacement which allowed for a partial correction of the condition, when the mandible moved forward to a normal centric relation, after the correction of the retroclined maxillary incisors position and creating an over jet. Levy, ${ }^{(7)}(1979)$ stated that "Clinicians often refer to correction of the incisor position in the Class II, Division 2 case as unlocking or a "freeing" of the mandible. This resultant freedom may be due to any one or a combination of three factors: positional changes of the condyles; rotational changes of the mandible; and actual growth of the maxillary and mandibular processes."Erickson and Hunter, ${ }^{(8)}(1985)$ followed a group of children with Class II, Division 2, during their orthodontic treatment, to 
Egyptian

Orthodontic Journal

investigate whether or not unlocking the bite enhances the anterior positioning of the mandible. They used the constant distance between Basion and Articulare, reported by Seward, ${ }^{(9)}(1981)$ and Ricketts et al, ${ }^{(5)}(1979)$, as an indicator for anterior mandibular repositioning, and reported that in approximately one-fourth of their sample, the basion-articulare distance increased more than $0.5 \mathrm{~mm} /$ year, which lead to the speculation that the increase in the distance could be a result of unlocking the mandible or might be only a temporary shift. More recently, Gong, Tao and Cao, ${ }^{(10)}$ (2003) conducted a clinical study on Class II, Division 2 deep-bite subjects, using 3D-CT and Sam-diagnostic articulator, to evaluate the changes of condylar position following the correction of the upper incisors inclination and opening of the bite. They found statistically significant changes of the sagittal and vertical condylar position in both sides, moving anteriorly and inferiorly.

The aim of this clinical study is to evaluate the condyle-fossa relationship, using CBCT scanning before and after the correction of the retroclined upper incisors in class II division 2 subjects, for the detection of possible mandibular functional displacement.

\section{MATERIALS AND METHODS}

Eleven subjects were enrolled in this study. Subjects were clinically diagnosed as Class II, Division 2 malocclusion, having the following criteria: Adult subjects with completed growth, the mean age was $24.55 \pm 3.36$ years, distal occlusion of the arches, no evident facial asymmetry, retroclined maxillary incisors, deep bite, presence of contact between the palatal surface of the maxillary incisors and the labial surface of the opposing mandibular incisors, no systemic diseases that may affect the TMJ, no history of trauma or surgery to the TMJ, and no history of previous orthodontic and/or orthopedic treatment. The sample was treated at the Orthodontic Department, Faculty of Dentistry, Alexandria University, after getting the ethical approval from the Alexandria University Ethical Committee. Informed consent was obtained from each subject before enrolling in the study. The mean treatment duration was $5.41 \pm 1.82$ months.

Volume 42 - December 2012 
After obtaining the full patient records, two CBCT scans were done for each subject, one before the start of the treatment and the second immediately after completion of the leveling stage.

Standardization of data acquisition and image processing of the two scans was a primary concern. A built in Laser beam was used to orient the subject's head so that the Frankfort plane is parallel and the mid-sagittal plane is perpendicular to the floor. Static head position was secured using the device cephalostat to ensure the accuracy and the reproducibility of the two scans. Patients were instructed to occlude in maximum intercuspation throughout the scan. ${ }^{(11)}$ All scans were obtained using the same device. ${ }^{*}$ The device performs volumetric study with a view field of $15 \times 15 \times 15 \mathrm{~cm}$, delivering a dose of $75 \mu \mathrm{Sv}$, at $85 \mathrm{kV}, 5-7$ $\mathrm{mA}$ in around 14 seconds. The same machine settings were adjusted by the same operator, before each scan, to ensure the standardization of the scan and the data acquisition. DICOM files were obtained on the workstation, $^{* *}$ the data were acquired with $0.3 \mathrm{~mm}$ slice thickness, with resolution of $1024 \times 1024$ image matrix and $0.3 / 0.15 \mathrm{~mm}$ isotropic voxel size.

The right and left TMJ areas were examined separately, for both the pre and post leveling CBCT scans of each subject. Each joint was considered as a separate case. The measuring procedure involved three main steps; slice selection, determination of the reference points and lines, and measuring of the joint spaces.

A mid-condylar slice was obtained by scrolling up and down the axial view of the subject's pre treatment scan; the widest diameter of the condylar head was selected and recorded for future reference, figure 1(a). The coronal view was used to determine the midpoint of the condylar head, figure 1(b). The same procedure was done in the post leveling scan, and the same diameter of the condylar head was obtained using the references from the pre leveling scan of the same patient.

\footnotetext{
* Galileos comfort, Sirona, Germany

${ }^{* *}$ Galaxis 1.9 , sirona dental technology, Germany
} 
Egyptian

Orthodontic Journal

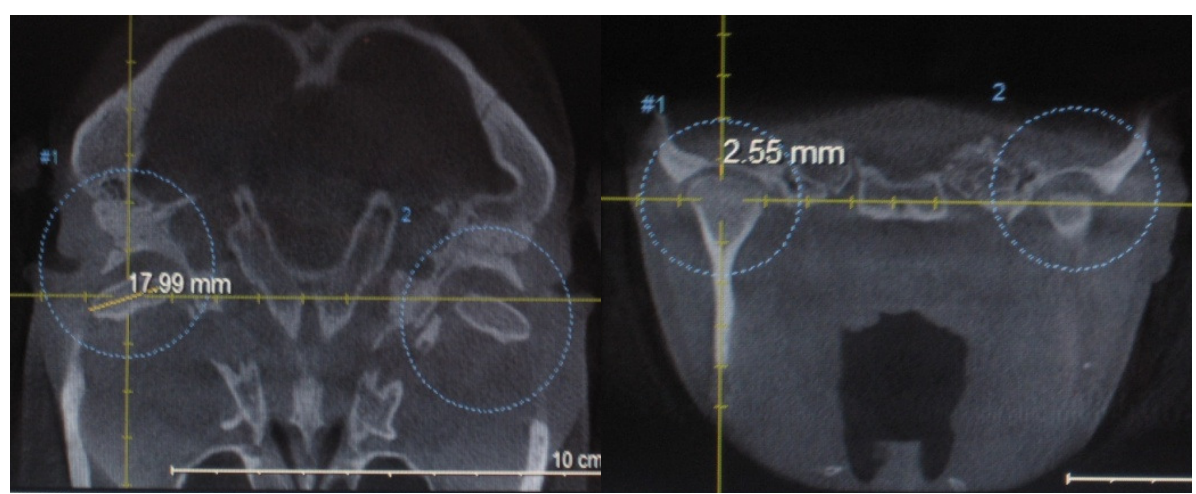

(a)

(b)

Figure (1): (a) Axial view of the CBCT, determination of the widest condylar diameter, (b)Coronal view of the $\mathrm{CBCT}$, determination of the mid condylar point

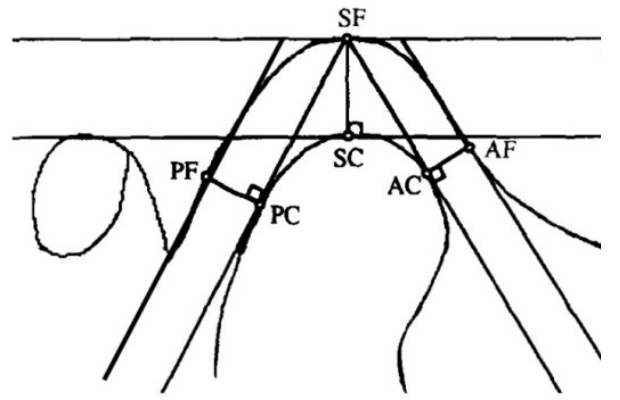

(a)

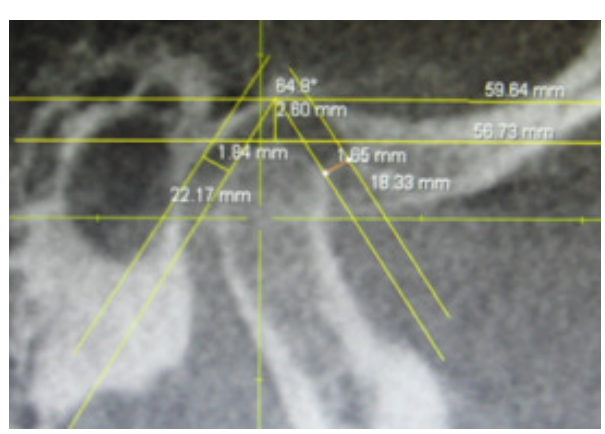

(b)

Figure (2): (a) Diagrammatic, (b) Radiographic illustration of the reference points and lines used for joint space measurements.

For the determination of the reference points and lines, the sagittal view was used since it was stated that it is the most appropriate for assessing the joint spaces. ${ }^{(12)}$ The method used for measuring the joint spaces is a modification of the method applied by Cohlmia et al. ${ }^{(13)}$ Location of the most superior (deepest) point of the glenoid fossa (SF) and the most superior point of the condylar head (SC). 
Two parallel tangent lines were drawn passing through the (SF) and (SC) points.

The most anterior $(\mathrm{AC})$ and the most posterior(PC) points of the condylar head were located. Two lines were drawn from the (SF) point to tangent the anterior and posterior condylar head surface at (AC) and (PC) point, respectively. Two lines were drawn parallel to the anterior and posterior condylar tangent lines, the two lines were drawn to tangent the anterior and posterior surfaces of the fossa, figure (2).

The superior (SJS), anterior (AJS) and posterior (PJS) joint spaces were measured by the perpendicular distances between each two parallel lines. In addition to the absolute joint measurements, the ratio of the joint spaces was calculated for each condyle, according to the method described by Gianelly et al, ${ }^{(11)}$ and was later used by others like Cohlmia et al. ${ }^{(13)}$ This ratio provides an index of condylar position. It was calculated by dividing the posterior joint space (PJS) by the anterior joint space (AJS). According to this ratio, the condyle is centered in the fossa when the value of the $\mathrm{P} / \mathrm{A}$ is in the range of 0.75 to 1.25 , posteriorly located when the $\mathrm{P} / \mathrm{A}<0.75$, and anteriorly located when the $\mathrm{P} / \mathrm{A}>1.25$.

Joint Space Index was also calculated for each condyle; a percentage was used by Pullinger et al, ${ }^{(14)}$ Cohlmia et al, ${ }^{(13)}$ and later by Ruf and Pancherz, ${ }^{(15)}$ as an indicator for the condylar position. A Joint Space Index (JSI) was calculated according to this formula [(PJS - AJS)/(PJS + AJS)] X 100. A zero value indicated a concentric location of the condyle within the fossa. A positive value indicated an anterior condylar position, and a negative value indicated a posterior position.

To ensure an accurate reproducibility of the same slice from the pre and post leveling CBCT scans of each subject, the slice selection and the determination of the reference points and lines of each TMJ was performed for both scans at the same time. For blinding, all scans were coded and randomized before the joint space measurements were taken. 
To detect the intra observer reliability, ten condyles were randomly selected, and the whole process was redone. The initial and the repeated measurements of these condyles were compared using the paired t test. The test did not show significant difference at the 0.05 level.

For these ten condyles, joint space measurements were also taken by a different examiner following the same steps, for the detection of the inter examiner reliability. The comparison between the two sets of measurements taken by the two different examiners was performed using the paired $t$ test. The result of the test did not show significant differences at the 0.05 level.

All measurements were taken by the same operator three times, and the mean of these readings were used for statistical analysis. The readings from the pre and post leveling scans were compared using the paired $\mathrm{t}$ test. Statistical analyses were done to assess the statistical significance of the results.

\section{RESULTS}

Table (1): Sample description according to age and treatment duration

\begin{tabular}{|l|c|}
\hline & $\begin{array}{c}\text { Subjects } \\
(\mathbf{n}=\mathbf{1 1})\end{array}$ \\
\hline Age (years) & $21.0-30.0$ \\
Min. - Max. & $24.55 \pm 3.36$ \\
Mean \pm SD & 23.0 \\
Median & \\
\hline Treatment duration & \\
(months) & $2.50-9.0$ \\
Min. - Max. & $5.41 \pm 1.82$ \\
Mean \pm SD & 5.0 \\
Median & \\
\hline
\end{tabular}

Volume 42 - December 2012 
Table (2): Comparison between the pre and post leveling results of the joint spaces measurements

\begin{tabular}{|l|c|c|c|}
\hline \multirow{2}{*}{} & \multicolumn{2}{|c|}{ Joint spaces measurements } & \multirow{2}{*|}{ P } \\
& Pre & Post & \\
\hline Superior (SJS) & & & \\
Min. - Max. & $2.24-4.62$ & $2.45-6.93$ & \multirow{2}{*}{$0.011^{*}$} \\
Mean \pm SD & $3.27 \pm 0.72$ & $3.68 \pm 1.19$ & \\
Median & 3.19 & 3.39 & \\
\hline Anterior (AJS) & & & $0.001^{*}$ \\
Min. - Max. & $1.02-2.73$ & $1.01-2.40$ & \\
Mean \pm SD & $1.94 \pm 0.46$ & $1.62 \pm 0.33$ & \\
Median & 1.87 & 1.66 & \multirow{2}{*}{$0.001^{*}$} \\
\hline Posterior (PJS) & & & \\
Min. - Max. & $1.33-4.54$ & $1.83-4.58$ & \\
Mean \pm SD & $2.59 \pm 0.78$ & $2.92 \pm 0.73$ & \\
Median & 2.60 & 2.88 & \\
\hline
\end{tabular}

$\mathrm{p}$ : $\mathrm{p}$ value for Paired t-test $*$ : Statistically significant at $\mathrm{p} \leq 0.05$

Table (3): Description of the condylar displacements according to the changes in the joint spaces measurements

\begin{tabular}{|l|c|c|c|}
\hline & $\begin{array}{c}\text { Changes in the } \\
\text { superior joint } \\
\text { space } \\
\text { (SJS) }\end{array}$ & $\begin{array}{c}\text { Changes in the } \\
\text { anterior joint } \\
\text { space } \\
\text { (AJS) }\end{array}$ & $\begin{array}{c}\text { Changes in the } \\
\text { posterior joint } \\
\text { space } \\
\text { (PJS) }\end{array}$ \\
\hline $\begin{array}{l}\text { Condylar displacement } \\
\text { in millimeters (n=22) }\end{array}$ & $0.0-2.69$ & $0.01-1.38$ & $0.06-1.39$ \\
Min. - Max. & $0.40 \pm 0.67$ & $0.33 \pm 0.38$ & $0.33 \pm 0.39$ \\
Mean \pm SD & 0.17 & 0.22 & 0.23 \\
\hline Median & & & \\
\hline
\end{tabular}

Volume 42-December 2012 
Table (4): Comparison between the pre and post leveling results according to the condylar position ratio and joint space index

\begin{tabular}{|l|c|c|c|}
\hline \multirow{2}{*}{} & \multicolumn{2}{|c|}{ Condylar position (n=22) } & \multirow{2}{*}{ P } \\
\cline { 2 - 3 } & Pre & Post & \\
\hline Ratio & $0.49-3.10$ & $1.0-3.49$ & \\
Min. - Max. & $1.46 \pm 0.70$ & $1.91 \pm 0.72$ & \multirow{2}{*}{$0.001^{*}$} \\
Mean \pm SD & 1.29 & 1.69 & \\
Median & & & \\
\hline Joint Space Index & $-34.59-51.19$ & $0.0-55.48$ & \multirow{2}{*}{$0.001^{*}$} \\
Min. - Max. & $12.88 \pm 21.80$ & $27.43 \pm 16.57$ & \\
Mean \pm SD & 12.74 & 25.75 & \\
Median & $* . S t a t i n$ & \\
\hline
\end{tabular}

p:p value for Paired t-test

*: Statistically significant at $\mathrm{p} \leq 0.05$

Table (5): Changes in condylar position according to pre and post condylar position ratios

\begin{tabular}{|c|c|c|c|c|c|c|}
\hline & \multicolumn{6}{|c|}{ Condylar position according to ratio (PJS/AJS) } \\
\hline & \multicolumn{2}{|c|}{$\begin{array}{c}\text { Posteriorly } \\
(<0.75)\end{array}$} & \multicolumn{2}{|c|}{$\begin{array}{c}\text { Centered } \\
(0.75 \text { to } 1.25)\end{array}$} & \multicolumn{2}{|c|}{$\begin{array}{c}\text { Anteriorly } \\
(>1.25)\end{array}$} \\
\hline & No & $\%$ & No & $\%$ & No & $\%$ \\
\hline Pre $(n=22)$ & 2 & 9.1 & 8 & 36.4 & 12 & 54.5 \\
\hline Post $(n=22)$ & 0 & 0.0 & 5 & 22.7 & 17 & 77.3 \\
\hline
\end{tabular}

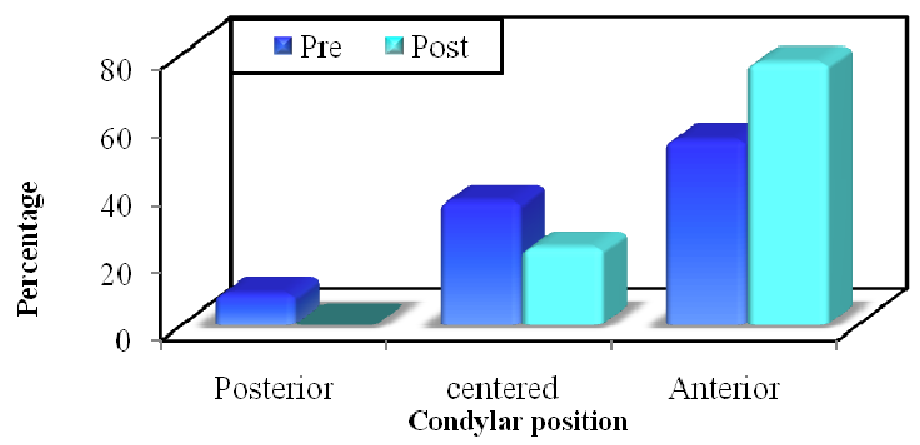

Figure (4): Bar chart showing the changes in condylar position according to pre and post condylar position ratios 
Table (6): Changes in condylar position according to pre and post Joint Space Index $(\mathrm{JSI})=[(\mathrm{PJS}-\mathrm{AJS}) /(\mathrm{PJS}+\mathrm{AJS})] \mathrm{X} 100$

\begin{tabular}{|l|c|c|c|c|c|c||}
\hline \multirow{2}{*}{} & \multicolumn{5}{|c|}{$\begin{array}{c}\text { Condylar position according to } \\
\text { Joint Space Index (JSI) }\end{array}$} \\
\cline { 2 - 7 } & \multicolumn{7}{|c|}{ Posterior(-ve) } & \multicolumn{2}{c|}{ Centered (= 0) } & \multicolumn{2}{c|}{ Anterior(+ ve) } \\
\cline { 2 - 7 } & No & $\mathbf{\%}$ & No & $\mathbf{\%}$ & No & $\%$ \\
\hline $\begin{array}{l}\text { Pre (n=22) } \\
\text { Post (n=22) }\end{array}$ & 6 & 27.3 & 0 & 0.0 & 16 & 72.7 \\
\cline { 2 - 7 } & 0 & 0.0 & 1 & 4.5 & 21 & 95.5 \\
\hline
\end{tabular}

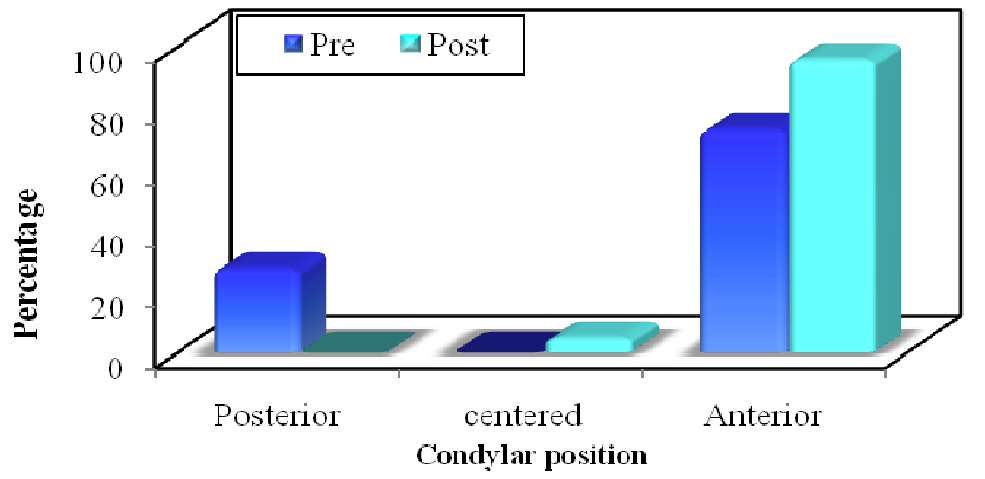

Figure (5): Bar chart showing the changes in condylar position according to pre and post Joint Space Index $(\mathrm{JSI})=[(\mathrm{PJS}-\mathrm{AJS}) /(\mathrm{PJS}+\mathrm{AJS})] \mathrm{X} 100$

The most obvious clinical observation was the marked increase of the over jet. All subjects commented on the newly developed gap between their maxillary and mandibular incisors with some phonetic disturbances. This was especially noted at the end of the leveling and alignment stage, where the retroclined position of the maxillary incisors was corrected while the lower incisors remained untouched in their retroclined position. Compared to the initial CBCT scan, the new incisors position made it easier for the subjects to occlude in centric occlusion with no interferences. The difference between the two scans was clear when the subjects were asked to occlude their teeth before taking the scans. The numerical data of this study are listed in tables (1) through (6) and figures (4), (5) with their statistical analyses. 
Egyptian

Orthodontic Journal

The descriptive data of the sample are shown in table (1).Statistical Analysis of the joint space measurementsis shown in table (2). The comparison of the pre and post leveling results using the Paired t-test showed statistically significant decrease in the anterior joint spaces, statistically significant increase in both the superior joint space, and the posterior joint spaces.

Table (3) describes condylar displacement in millimeters, judged by the changes of the joint spaces measurements. The mean increase of the superior joint space was $0.4 \pm 0.67 \mathrm{~mm}$, the mean decrease in the anterior joint space was $0.33 \pm 0.38 \mathrm{~mm}$, and the mean increase of the posterior joint space was $0.33 \pm 0.39 \mathrm{~mm}$.

Table (4) shows the comparison between the pre and post leveling ratios and joint space index of the condylar position. The Paired t-test showed statistically significant increase in both the condylar position ratios and joint space index.

The distribution of the studied cases according to the pre and post ratios of the condylar position is shown in table (5) and figure (4). Initially, two $(9.1 \%)$ of the total 22 condyles were posteriorly positioned, $8(36.4 \%)$ were centered, and $12(54.5 \%)$ were anteriorly positioned. The post leveling ratio shows that 5 condyles $(22.7 \%)$ were centered, and $17(77.3 \%)$ were anteriorly positioned. This means that the number of posteriorly located condyles dropped from 2 to zero, the number of centered condyles dropped from 8 to 5 , while the number of the anteriorly positioned condyles increased from 12 to 17.According to the condylar position ratio, the total number of condyles that have shifted forward was $5(22.7 \%)$, out of the total 22 condyles.

The distribution of the studied cases according to the Joint Space Indexis shown in table (6) and figure (5). The pre leveling data reveals that 6 condyles $(27.3 \%)$ were posteriorly positioned, and $16(72.7 \%)$ were anteriorly positioned. This was changed to $1(4.5 \%)$ centered, and 21 $(95.5 \%)$ anteriorly located condylesin the post leveling stage. These results show that the number of posteriorly located condyles dropped from 6 to zero, the number of centered condyles increased from zero to 1 , while the number of the anteriorly positioned condyles increased from 16 to 21 condyles. According to the joint space index, the total number of condyles that have shifted forward was $6(27.2 \%)$, out of the total 22 condyles. 
Egyptian

Orthodontic Journal

\section{DISCUSSION}

The relation between deep-bite, contacting incisors relationship and condylar retroposition is of clinical importance because it may affect the treatment strategies. Blackwood, ${ }^{(16)}$ (1969) reported that the articular tissues have considerable potential for adaptation to changing functional demands. This study tested the hypothesis that, subjects with Class II, Division 2 malocclusion with retroclined maxillary incisors, deep bite and contacting incisors may develop posterior functional displacement of the mandible, which may shift anteriorly with the correction of the maxillary incisor retroclination.

Several studies compared joints space measurements of a study group and a separate control group. However, the individual variability of the condylar position requires large sample size, to compare the average position between the different study groups. On the other hand, direct comparison of the joint space measurements from the pre and post treatment scans of the same subject provides more sensitive assessment of condylar displacement. ${ }^{(17)}$

Moreover, studies that used direct comparison of the pre and post treatment measurements usually utilized corrected tomograms, where the validity of tomographic tracings to measure small changes in condylar position has been questioned. ${ }^{(18)}$ In addition, this technique has some limitations. First, the reproducibility of the joint space measurements on repeated exposures of the same subject with this technique is not known. ${ }^{(17)}$ Second, variation of the head position within the cephalostat can affect the depth of cut and slice angulations, at least to some degree ${ }^{(17)}$ and because joint space dimensions are not consistent in the lateral, central, and medial positions of the joint, ${ }^{(19)}$ the variation in depth of cut may affect reproducibility.

Trying to avoid these limitations, this study was designed to use direct comparison of the pre and post condylar positions of the same subjects using CBCT scans.

The selection of the CBCT technique was preferred to the 3D-MSCT for some reasons. First, the reduced exposure dosage compared to spiral CT. Many authors, ${ }^{(20-23)}$ reported that the CBCT offers lower effective dose 
than the conventional computed tomography (CT), for imaging of the cranium. In addition, the standing or sitting patient positioning in the CBCT technique provides more physiological condylar position, compared to the supine patient positioning in the MSCT, where the gravity may have an effect on the condyle-fossa relation. Finally, the incorporation of the cephalostat and the laser beam in the CBCT machine ensured the accurate head positioning and control head rotation for the accurate reproducibility of standardized scans.

This study included 11 subjects. The sample size estimation was done according to the formula $n=Z^{2} S^{2} / E^{2}$, where $(Z)$ is the Confidence Coefficient, (S) is the Standard deviation, and (E) is the acceptable Error. The limited sample size may have affected the results so that changes of minimal values resulted in statistical significance. For statistical purposes some studies considered each joint a separate case,${ }^{(24,25)}$ the same concept was used in our study.

The sample included adult subjects (mean age $24.55 \pm 3.36$ years), with completed growth to eliminate the effect of growth on both the dimensional and the positional status of the fossae or the condyles.

The anterior joint space could be altered independent of the posterior joint space if the condyle rotates as a change in the vertical dimension. It may also be affected by articular surface remodeling of both the condyle and articular eminence. ${ }^{(17)}$ The effect of remodeling is not likely the case in this study because of the relatively short time between the two exams.

The results reveal that the number of the condyles that demonstrated anterior shift after leveling of the maxillary arch, were $6(27.2 \%)$ condyles, judged by the Joint space index (JSI), and 5 (22.7) condyles judged by the condylar position ratio.

These results are in agreement with other studies. Ricketts ${ }^{(26)}$ noted that in some Class II, Division 2 malocclusions subjects, the mandible followed the maxillary incisors teeth after they were tipped labially in the initial phase of treatment. Many authors, ${ }^{(27-29)}$ agreed that deep-bite with contacting incisor relationships can cause posterior condylar displacement, especially if combined with lingually inclined incisors, 
Egyptian

Orthodontic Journal

because the incisors can create interferences that cause a distal path of closure. Farrar and McCarty ${ }^{(28)}$ stated that "the entire mandible begins to be displaced posteriorly." Gong et $\mathrm{al}^{(10)}$ (2003) also found that with the increase of inclination of upper incisors and bite opening, there were statistically significant changes of the condylar position moving anteriorly and inferiorly.

On the hand, many studies disagreed with the results of this study. Litt and Nielsen, ${ }^{(30)}$ (1984) found that the mandible remained stationary after proclination of the upper incisors in Class II division 2 subjects. Pullinger et $\mathrm{al}^{(31)}(1987)$ showed that there is no increased risk of condylar retroposition in individuals with deep bite and found no correlation between incisal overbite and over jet and condylar position. Even when overbite and over jet were factored together to approximateincisal guidance, there was still no association.

Gianelly, Petras and Boffa, ${ }^{(24)}$ (1989) studied the condylar position of 19 click-free Class II subjects with bite depth exceeding 50\%, contacting incisors relationship, and aninterincisal angle of greater than 140 . Their investigations revealed that these factors do not appear to predispos to condylar retro position, and that the condyles of these cases were positioned concentrically in the fossa. They did not believe that the correction of the overbite will allow the mandible to shift forward. However, they used corrected tomograms, a technique that has many limitations ${ }^{(17-19)}$ The sample age ranged from 9 to 35 years, a factor that might have affected condylar position in different age groups. ${ }^{(32)}$ In their study, only 6 out of the total 19 subjects had lingually inclined central incisors and labially positioned laterals. Finally, the study did not directly test the effect of unlocking the bite on the condylar position on the same subjects, rather they compared Class II with and without deep bite.

When Demisch et $\mathrm{al}^{(2)}$ (1992) studied the effect of treatment of Class II, Division 2 on mandibular displacement. Spontaneous anterior mandibular repositioning after proclination of the maxillary incisors was not validated. Some reasons may have led to this result. First, the subjects' age ranged from 8 to 12 years, with growth potential. The authors reported small but significant growth of the maxilla in the 
Egyptian

Orthodontic Journal

anterior direction, a factor that may have masked occlusal detection of any mandibular anterior repositioning. Second, wax bites and mounted dental casts were used for recording of the relation between the retruded (RCP) and the intercuspal (ICP) mandibular position. The measuring point was located at the gingival papilla between the mandibular central incisors, which might not be a stable reproducible point, as the thickness and location of the papilla might be affected by gingival inflammation, and the proclination of the lower incisors with the use of the activators. In addition, the recording of the intercuspal relation was done by the subject, while the recording of the retruded cuspal position was guided by the examiner. The mandible had to be forced posteriorly then moved to the first tooth contact. This depends on how much the muscle was relaxed, and how much pressure was applied by the examiner. Furthermore, the recording of the relation between RCP and ICP was done 12 months after the start of treatment. At that point, four subjects had completed the $2^{\text {nd }}$ phase of treatment; twelve were still in that phase, and five were already in the $3^{\text {rd }}$ phase. The lack of standardization of the point at which the bite recording was performed may have affected the reliability of their results. Finally, the appliance they used for proclination of the upper incisors incorporated anterior bite plates that kept the posterior teeth free to erupt for the correction of the deep bite, leading to downward and backward rotation of the mandible. This was evident by the increase of the facial height, mandibular inclination, and occlusal plane inclination. This rotation may have canceled or reduced the effect of the anterior mandibular repositioning on the change of the RCP/ICP distance.

\section{SUMMARY AND CONCLUSION}

The aim of this study was to evaluate the condyle-fossa relationship, using CBCT scanning before and after the correction of retroclined upper incisors in Class II, Division 2 subjects, for the detection of possible mandibular functional displacement.

The sample consisted of 11 Class II, Division 2 subjects with mean age of $24.55 \pm 3.36$ years. A CBCT scans was obtained for each subject before and after leveling of the maxillary arch. Comparison of the joint space measurements was done for detection of condylar displacement. 
Egyptian

Orthodontic Journal

The Null hypothesis was rejected. The statistical analysis of the absolute and percentage changes of the pre and post condylar position showed statistically significant differences. The sample showed statistically significant decrease in the anterior joint spaces, statistically significant increase in the superior joint space, the posterior joint spaces, with significant changes in the condylar position ratio and percentage.

The correction of the maxillary Incisors retroclination in Class II, Division 2 subjects, showed statistically significant functional displacement of the condylar position moving anteriorly and inferiorly. The mean changes of the condylar position was $0.4 \pm 0.67 \mathrm{~mm}$ for superior joint space, $0.33 \pm 0.38 \mathrm{~mm}$, and $0.33 \pm 0.39 \mathrm{~mm}$ for the anterior, and posterior joint space respectively. However, the clinical significance of these values is yet to be investigated.

\section{REFERENCES}

1. Ingervall B. Relation between retruded contact, intercuspal, and rest positions of mandible in children with angle Class II, Division 2 malocclusion. Odontol Revy. 1968;19(3):293-310.

2. Demisch A, Ingervall B, Thuer U. Mandibular displacement in Angle Class II, division 2 malocclusion. Am J Orthod Dentofacial Orthop. 1992 Dec;102(6):509-18.

3. Thüer U, Ingervall B, Bürgin W, Demisch A. No posterior mandibular displacement in Angle Class II, division 2 malocclusion as revealed with electromyography and sirognathography. European Journal of Orthodontics. 1992;14(2):162-71.

4. Taylor A. Release mechanisms in the treatment of Class II, Division 2 malocclusions. Aust Dent J. 1966;11:27-37.

5. Ricketts R, Bench R, Gugino C, Hilgers J, R. S. Bioprogressive Therapy. Book 1, 2nd ed. Denver: Rocky Mt. Orthod; 1979.

6. Swann G. The diagnosis and interpretation of Class II, Division 2. Am J Orthod. 1954;40:325-40.

7. Levy P. Growth of the mandible after correction of the Class II, Division 2 malocclusion: UCLA School of Dentistry; 1979.

8. Erickson L, Hunter W. Class II, Division 2 treatment and mandibular growth. Angle Orthod. 1985;55:215-24. 
9. Seward S. Relation of basion to articulare. Angle Orthod. 1981 Apr;51(2):151-61.

10. Gong $\mathrm{f}$, Tao L, Cao H. A clinical study of the changes of condylar position in class II division 2 deep bite patients after orthodontic treatment. Shanghai Kou Qiang Yi Xue. 2003;Oct;12(5):334-7 [Abstract].

11. Gianelly AA, Hughes HM, Wohlgemuth P, Gildea G. Condylar position and extraction treatment. Am J Orthod Dentofacial Orthop. 1988 Mar;93(3):201-5.

12. Rodrigues AF, Fraga MR, Vitral RW. Computed tomography evaluation of the temporomandibular joint in Class II Division 1 and Class III malocclusion patients: condylar symmetry and condyle-fossa relationship. Am J Orthod Dentofacial Orthop. 2009 Aug;136(2):199-206.

13. Cohlmia JT, Ghosh J, Sinha PK, Nanda RS, Currier GF. Tomographic assessment of temporomandibular joints in patients with malocclusion. Angle Orthod. 1996;66(1):27-35.

14. Pullinger AG, Hollender L, Solberg WK, Petersson A. A tomographic study of mandibular condyle position in an asymptomatic population. J Prosthet Dent. 1985 May;53(5):706-13.

15. Ruf S, Pancherz H. Does bite-jumping damage the TMJ? A prospective longitudinal clinical and MRI study of Herbst patients. Angle Orthod. 2000 Jun;70(3):183-99.

16. Blackwood HJ. Pathology of the tempromandibular joint. J Am Dent Assoc. 1969;79:118-24.

17. Major P, Kamelchuk L, Nebbe B, Petrikowski G, Glover K. Condyle displacement associated with premolar extraction and nonextraction orthodontic treatment of Class I malocclusion. Am J Orthod Dentofacial Orthop. 1997 Oct;112(4):435-40.

18. Girardot RA, Jr. Comparison of condylar position in hyperdivergent and hypodivergent facial skeletal types. Angle Orthod. 2001 Aug;71(4):240-6.

19. Hatcher DC, Blom RJ, Baker CG. Temporomandibular joint spatial relationships: osseous and soft tissues. J Prosthet Dent. 1986 Sep;56(3):344-53.

20. Loubele M, Bogaerts R, Van Dijck E, Pauwels R, Vanheusden S, Suetens $\mathrm{P}$, et al. Comparison between effective radiation dose of CBCT and MSCT scanners for dentomaxillofacial applications. Eur J Radiol. 2009 Sep;71(3):461-8. 
21. Swennen GR, Schutyser F. Three-dimensional cephalometry: spiral multi-slice vs cone-beam computed tomography. Am J Orthod Dentofacial Orthop. 2006 Sep;130(3):410-6.

22. Suomalainen A, Kiljunen T, Kaser Y, Peltola J, Kortesniemi M. Dosimetry and image quality of four dental cone beam computed tomography scanners compared with multislice computed tomography scanners. Dentomaxillofac Radiol. 2009 Sep;38(6):367-78.

23. Ludlow JB, Ivanovic M. Comparative dosimetry of dental CBCT devices and 64-slice CT for oral and maxillofacial radiology. Oral Surg Oral Med Oral Pathol Oral Radiol Endod. 2008 Jul;106(1):106-14.

24. Gianelly AA, Petras JC, Boffa J. Condylar position and Class II deep-bite, no-overjet malocclusions. Am J Orthod Dentofacial Orthop. 1989 Nov;96(5):428-32.

25. Kinniburgh R, Major P, Nebbe B, West K, Glover K. Osseous Morphology and Spatial Relationships of the Temporomandibular Joint: Comparisons of Normal and Anterior Disc Positions. Angle Orthod. $2000 \mathrm{Feb} ; 70(1): 70-80$.

26. Ricketts R. A study of changes in temporomandibular relations associated with the treatment of Class II malocclusion. Am J Orthod. 1952;38:918-33.

27. Ricketts R. Abnormal function of the tempromandibular joint and related musculature. Am J Orthod. 1955;41:435-41.

28. Farrar W, McCarty W. A clinical outline of tempromandibular joint diagnosis and treatment. Montgomery, Alabama: Walker Print; 1983.

29. Thompson JR. Abnormal function of the temporomandibular joints and related musculature. Orthodontic implications. Part II. Angle Orthod. 1986 Jul;56(3):181-95.

30. Litt RA, Nielsen IL. Interceptive treatment of Class II, Division 2. Eur J Orthod. 1984 Aug;6(3):213-30.

31. Pullinger AG, Solberg WK, Hollender L, Petersson A. Relationship of mandibular condylar position to dental occlusion factors in an asymptomatic population. Am J Orthod Dentofacial Orthop. 1987 Mar;91(3):200-6.

32. High $\mathrm{H}$, Westminster $\mathrm{N}$, Pottinger M. Condyle position in the untreated orthodontic patient. Foundation Orthod Res. 1978:39-42. 